\title{
microRNA-33a-5p increases radiosensitivity by inhibiting glycolysis in melanoma
}

\author{
Ke Cao ${ }^{1, *}$, Jingjing $\mathrm{Li}^{2,}{ }^{*}$, Jia Chen ${ }^{2, *}$, Li Qian ${ }^{3}$, Aijun Wang ${ }^{4}$, Xiang Chen ${ }^{5}$, Wei Xiong ${ }^{6}$, Jintian \\ Tang $^{7}$, Shijie Tang ${ }^{8}$, Yong Chen ${ }^{9}$, Yao Chen ${ }^{2}$, Yan Cheng ${ }^{10}$ and Jianda Zhou ${ }^{2}$ \\ ${ }^{1}$ Department of Oncology of Third Xiangya Hospital, Central South University, Changsha, China \\ ${ }^{2}$ Department of Plastic Surgery of Third Xiangya Hospital, Central South University, Changsha, China \\ ${ }^{3}$ Department of Burn and Plastic Surgery of Second Xiangya Hospital, Central South University, Changsha, China \\ ${ }^{4}$ Surgical Bioengineering Laboratory, Department of Surgery, UC Davis School of Medicine, Sacramento, California, USA \\ ${ }^{5}$ Department of Dermatology of Xiangya Hospital, Central South University, Changsha, China \\ ${ }^{6}$ Cancer Research Institute, Key Laboratory of Carcinogenesis of Ministry of Health, Central South University, Changsha, China \\ ${ }^{7}$ Institute of Medical Physics and Engineering, Department of Engineering Physics, Tsinghua University, Beijing, China \\ ${ }^{8}$ Department of Plastic Surgery, Second Hospital of Shantou University, Shantou, China \\ ${ }^{9}$ Key Laboratory of Genetics and Birth Health of Hunan Province, Family Planning Institute of Hunan Province, Changsha, \\ China \\ ${ }^{10}$ School of Pharmaceutical sciences, Central South University, Changsha, China \\ *These authors contributed equally to this work \\ Correspondence to: Jianda Zhou, email: doctorzhoujianda@163.com \\ Yan Cheng, email: yancheng@csu.edu.cn \\ Yao Chen, email: 99392587@qq.com
}

Keywords: microRNA, radiation, glucose, HIF-1a, lactate dehydrogenase $A$

Received: January 10, 2017 Accepted: June 19, $2017 \quad$ Published: July 05, 2017

Copyright: Cao et al. This is an open-access article distributed under the terms of the Creative Commons Attribution License 3.0 (CC BY 3.0), which permits unrestricted use, distribution, and reproduction in any medium, provided the original author and source are credited.

\section{ABSTRACT}

Glycolysis was reported to have a positive correlation with radioresistance. Our previous study found that the miR-33a functioned as a tumor suppressor in malignant melanoma by targeting hypoxia-inducible factor1-alpha (HIF-1a), a gene known to promote glycolysis. However, the role of miR-33a-5p in radiosensitivity remains to be elucidated. We found that miR-33a-5p was downregulated in melanoma tissues and cells. Cell proliferation was downregulated after overexpression of miR$33 a-5 p$ in WM451 cells, accompanied by a decreased level of glycolysis. In contrast, cell proliferation was upregulated after inhibition of miR-33a-5p in WM35 cells, accompanied by increased glycolysis. Overexpression of miR-33a-5p enhanced the sensitivity of melanoma cells to X-radiation by MTT assay, while downregulation of miR-33a-5p had the opposite effects. Finally, in vivo experiments with xenografts in nude mice confirmed that high expression of miR-33a-5p in tumor cells increased radiosensitivity via inhibiting glycolysis. In conclusions, miR-33a-5p promotes radiosensitivity by negatively regulating glycolysis in melanoma.

\section{INTRODUCTION}

Malignant melanoma (MM), an aggressive skin malignancy, is the fifth most common malignant tumor in men and the seventh most common malignant tumor in women $[1,2]$. Recent studies showed that the incidence of MM has increased by 3.1\% per year [3]. Despite significant advances in early detection and treatment of $\mathrm{MM}$, the prognosis of MM remains poor [4, 5]. Radiation is an important treatment modality for melanoma, therefore methods of increasing the radiosensitivity of melanoma cells are urgently needed. 
Increased glucose uptake and accumulation of lactate are common features of cancer cells. Lactate accumulation is considered an early event of malignant tumors and promotes radiation resistance in solid tumors [6]. Sattler et al. [7] reported that tumor glycolysis is associated with inhibition of reactive oxygen species (ROS)-mediated fixation of DNA damage and induction of radioresistance. Aerobic glycolysis generates a chemically reduced milieu associated with the development of radioresistance in cancer cells, suggesting a significant therapeutic gain for combination with glycolysis inhibitors in radiotherapy [6,8-10]. Furthermore, inhibitors of glycolysis, including 2-deoxy-d-glucose and oxamate (an inhibitor of lactate dehydrogenase A) [11, 12], obviously enhanced the sensitivity to radiotherapy. A combination of 2-deoxy-d-glucose and 6-aminonicotinamide (6-AN, an inhibitor of the pentose phosphate pathway) increased the radiosensitivity of neck cancer cells by activating ASK1/JNK/p38 MAPK signaling [13, 14]. Resistance to radiotherapy is considered to be an important factor limiting the efficacy of melanoma treatment. Therefore, developing effective targeting agents of glycolysis may provide alternative therapeutic strategies for enhancing MM radiosensitivity.

MicroRNAs (miRNAs) regulate gene expression by inhibiting gene translation or facilitating mRNA degradation [15, 16]. In recent years, accumulating evidence has revealed that miRNAs negatively modulate a variety of genes pivotal for tumor development [17-20]. miR-33a has been found to play a key role of tumor suppressor in several human cancers. For instance, Du M et al. [21] showed that miR-33a suppressed proliferation of non-small-cell lung carcinoma cells via targeting oncogene METTL3 and Kuo et al. [22] found that miR33 a functioned as a bone metastasis suppressor in lung cancer. In our previous study, we showed that miR-33a functions as a tumor suppressor by targeting HIF-1 $\alpha$ in melanoma [23]. HIF-1 $\alpha$ has been demonstrated to act as a key regulator in glycolysis [24]. However, the detailed functions of miR-33a-5p in MM cell radiosensitivity and the underlying molecular mechanism remains largely unclear. Not only that, related mechanisms of miRNAs negatively regulate glycolysis in melanoma radiotherapy has not been reported before. In the present study, we aimed to elucidate whether miR-33a-5p increases MM cell radiosensitivity by inhibiting glycolysis. Our data suggest that miR-33a-5p might be a promising molecular target for melanoma therapy.

\section{RESULTS}

\section{Melanoma tissue and cell lines have lower miR- 33a-5p expression level}

To explore the role of miR-33a-5p in MM, we first examined the expression level of miR-33a-5p in melanoma and nevus tissues by qRT-PCR and found that miR-33a-5p was significantly downregulated in carcinoma tissue compared with nevus tissue. Interestingly, the miR-33a-5p level in metastatic tissue specimens was much lower than that in primary tumor tissues (Figure 1A). We further examined the expression level of miR-33a-5p in three MM cell lines, WM35, WM451, and SK-MEL-1 and human melanocytes (HM). As shown in Figure 1B, the expression of miR-33a-5p was significantly downregulated in WM35, WM451 and SK-MEL-1 cells compared to HM cells. Based on these preliminary data, we chose WM35 and WM451 cells to further investigate the role of miR-33a-5p in $\mathrm{MM}$ in vitro.

\section{miR-33a-5p inhibits the viability of melanoma cells}

The expression of miR-33a-5p was low in WM35 and WM451 cells, but much lower in WM451 cells, we transfected WM451 cells with pre-miR-33a-5p labeled green fluorescent protein plasmid and WM35 cells with anti-miR-33a-5p labeled green fluorescent protein plasmid. The transfection efficiency was evaluated by fluorescence microscopy and qRT-PCR. The green fluorescence representes the transfection efficiency of each plasmid. Over 80\% of WM35 (Figure 1C) and WM451 (Figure 1D) cells were stained in green fluorescence, which suggesting the transfection efficiency was satisfied. The results of qRT-PCR show that miR-33a-5p expression in WM35 cells was notably reduced after transfection with anti-miR-33a-5p plasmid (Figure 1E) whereas expression in WM451 cells was increased after transfection with pre-miR-33a-5p plasmid (Figure $1 \mathrm{G}$ ), confirming that the transfections were successful.

Cell viability in each group was determined by MTT assay and found that cell proliferation was upregulated after inhibition of miR-33a-5p in WM35 cells (Figure 1F) but was downregulated after overexpression of miR-33a-5p in WM451 cells (Figure 1H), suggesting that miR-33a-5p plays an inhibitory role in MM cell proliferation.

\section{miR-33a-5p inhibits glycolysis in melanoma cells}

As glycolysis functions as a promoter in radiosensitivity, we determined the glycolysis level in each group of cells. HIF-1 is a key regulator of cellular and systemic homeostatic responses to hypoxia through the activation of gene transcription, and is involved in energy metabolism, angiogenesis, and apoptosis [25, 26]. In our previous study, we confirmed that HIF-1 $\alpha$ is a direct gene target of miR-33a in melanoma [22]. Furthermore, HIF-1 $\alpha$ has been demonstrated to act as a key regulator in glycolysis, HIF-1 $\alpha$ is the best-known transcriptional regulators controlling expression of glycolysis genes, such as HK1, HK2, and LDHA, whose expression levels are highly elevated in cancer cells [27]. As shown in 
A

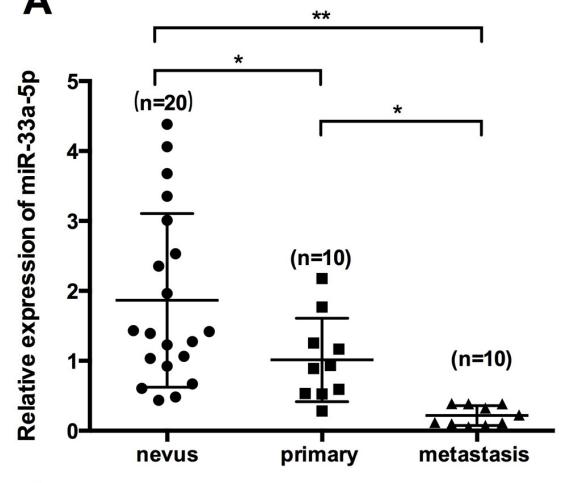

C

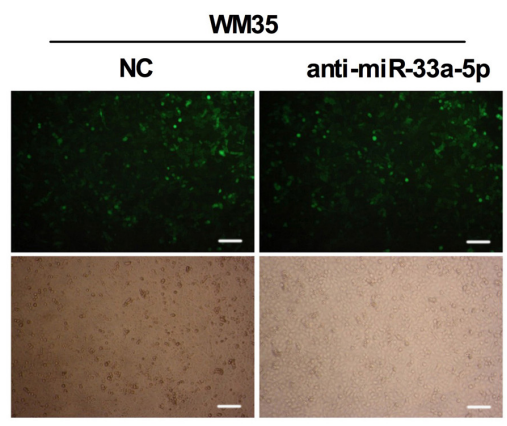

E

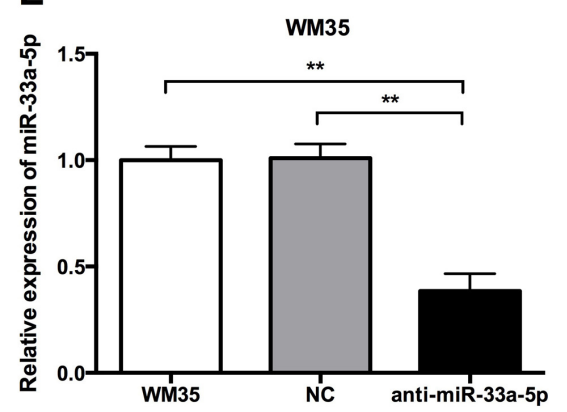

G

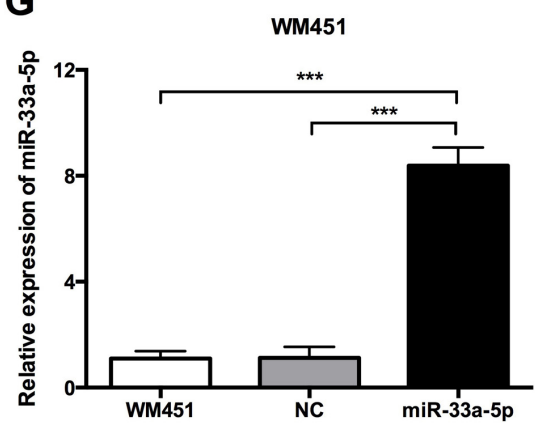

B

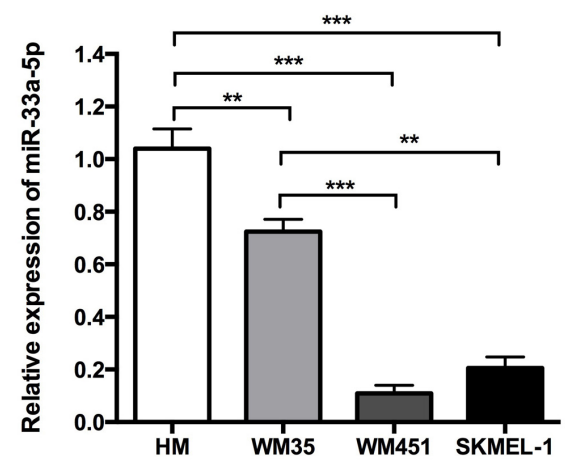

D

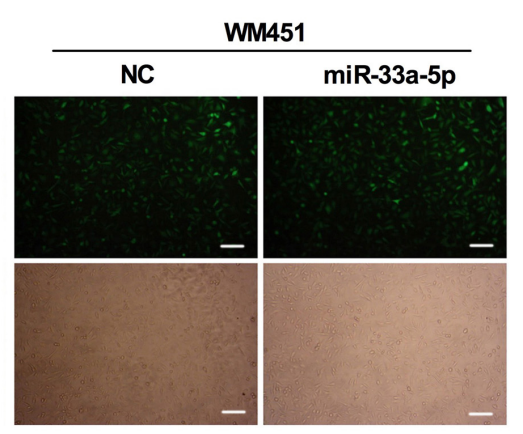

$\mathbf{F}$

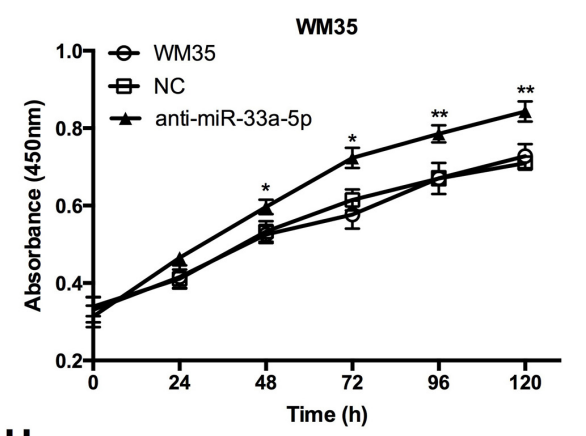

H

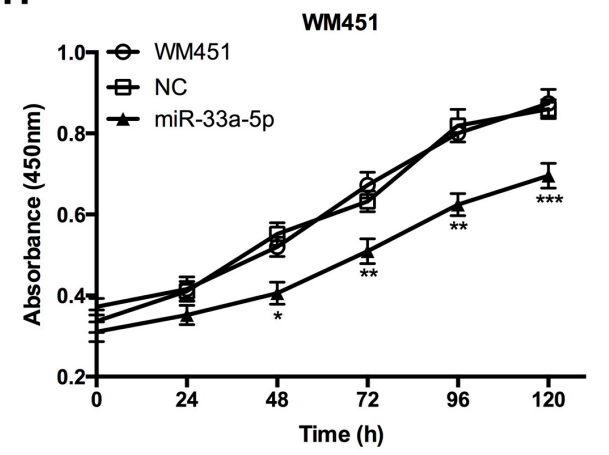

Figure 1: Expression of miR-33a-5p in MM tissue and cell lines. (A) miR-33a-5p expression was significantly downregulated in MM tissue samples compared with nevus by qRT-PCR. miR-33a-5p expression was also lower in metastatic tissue compared with primary tumor tissue. (B) qRT-PCR was performed to analyze the expression level of miR-33a-5p in three MM cell lines (WM35, WM451, and SKMEL-1) and human melanocytes (HM). (C) WM35 cells were transfected with normal control (NC) or anti-miR-33a-5p (anti-miR-33a-5p) lentivirus plasmids. Representative fluorescence microscopy (top) and bright field microscopic images (bottom) are shown in the left panel. (D) WM451 cells were transfected with NC (NC) or pre-miR-33a-5p (miR-33a-5p) lentivirus plasmids. Representative fluorescence microscopy (top) and bright field microscopic images (bottom) are shown in the right panel. (E) qRT-PCR analysis of miR-33a-5p expression relative to that in untreated WM35 cells (set as 1). (F) WM35 cell proliferation at the indicated time points determined by MTT assay. (G) qRT-PCR analysis of miR-33a-5p expression relative to that in non-treated WM451 cells (set as 1). (H) WM451 cell proliferation at the indicated time points determined by MTT assay. Scal bar: $50 \mu \mathrm{m} .{ }^{*} P<0.05,{ }^{*} P<0.01,{ }^{* * *} P<0.001$. 
Figure 2A, 2B, the expression of HIF-1 $\alpha$, HK1, HK2, and LDH-A was notably increased after inhibition of miR-33a-5p in WM35 cells, but reduced after miR-33a$5 \mathrm{p}$ overexpression in WM451 cells. These results suggest that miR-33a-5p inhibits glycolysis in MM cells, and that HIF- $1 \alpha$ is involved in this inhibitory activity.

Glucose uptake and LDH-A activity are main indicators of glucose metabolism. Lactic acid production, and ATP production were also measured to evaluate the glycolysis level, which are main products of glycolysis. As shown in Figure 3A-3D, lactic acid production, LDH-A activity, and ATP production were notably upregulated after inhibition of miR-33a-5p in WM35 cells, but all four parameters were downregulated after miR-33a-5p overexpression in WM451 cells. These findings further suggested that miR-33a-5p plays a suppressive role in the regulation of glycolysis in MM cells.

\section{HIF-1 $\alpha$ is involved in miR-33a-5p-mediated glycolysis in melanoma cells}

To further investigate whether HIF-1 $\alpha$ acts as a downstream effecter in miR-33a-5p-mediated glycolysis in
MM cells, we constructed 3 shRNA (small hairpin RNA) expression plasmids targeting HIF- $1 \alpha$, and then transfected into WM451 cells by lipofectamine methods. Western blotting was performed to detect the expression of HIF-1 $\alpha$ protein (Figure 4A).Western blotting results revealed that the third shRNA sequence had the best inhibitory effect, sh3-HIF-1 $\alpha$ plasmid was chose for further investigation. The cell proliferation after co-transfection with anti-miR-33a-5p and shHIF- $1 \alpha$ plasmids or miR-33a-5p and HIF- $1 \alpha$ plasmids were presented in supplementary materials. The results showed that HIF-1 $\alpha$ significantly restored the inhibitory effect of miR-33a-5p (Supplementary Figure 1). WM35 cells were transfected with anti-miR-33a-5p plasmid or co-transfected them with two lasmids expressing anti-miR$33 a-5 p$ and sh3-HIF-1 $\alpha$, respectively. WM451 cells were transfected with pre-miR-33a-5p plasmid, or co-transfected them with two plasmids expressing pre-miR-33a-5p and HIF-1 $\alpha$, respectively. Glycolysis level was examined in each group. As shown in Figure 4B, downregulation of HIF-1 $\alpha$ reversed the promoting effect of miR-33a-5p inhibition on glycolysis in WM35 cells, whereas upregulation of HIF-1 $\alpha$ reversed the inhibitory effect of miR-33a-5p overexpression on glycolysis in WM451 cells.
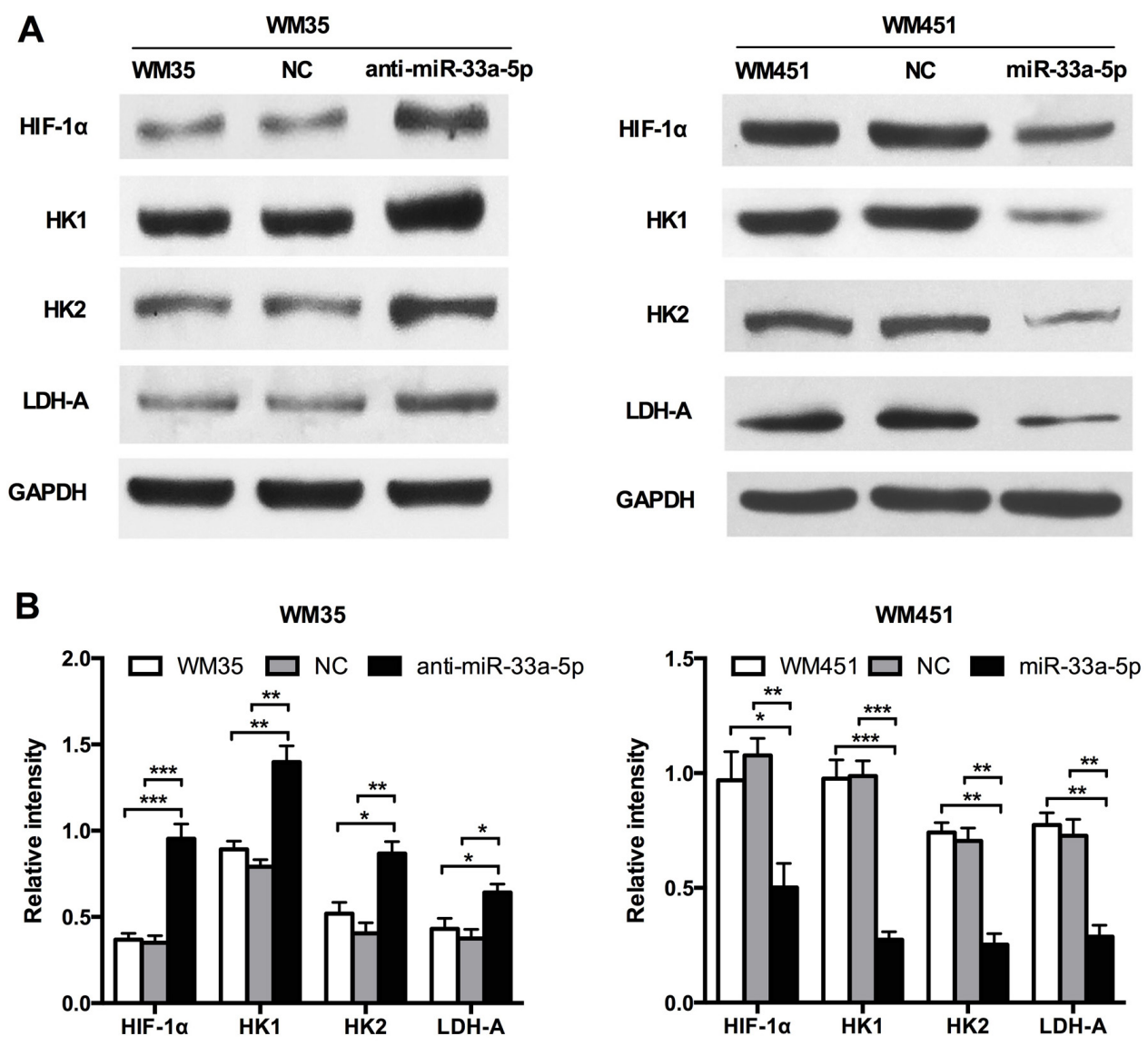

Figure 2: miR-33a-5p targets the glycolysis signaling pathway in MM. (A) Western blot analysis of HIF-1 $\alpha$, HK1, HK2, and LDH-A protein expression in WM35 and WM451 cells. GAPDH protein expression was used as a control for input and normalization. (B) Quantitative graph showing the image intensity for WM35 and WM451 cells shown in A. ${ }^{*} P<0.05,{ }^{*} P<0.01,{ }^{* * *} P<0.001$. 
Glucose consumption, lactic acid production, LDH-A activity, and ATP production were measured to evaluate the glycolysis level. Figure 5A-5D shows that the glucose consumption, lactic acid production, LDH-A activity, and ATP production were notably reduced in WM35 cells after co-transfection with anti-miR-33a-5p
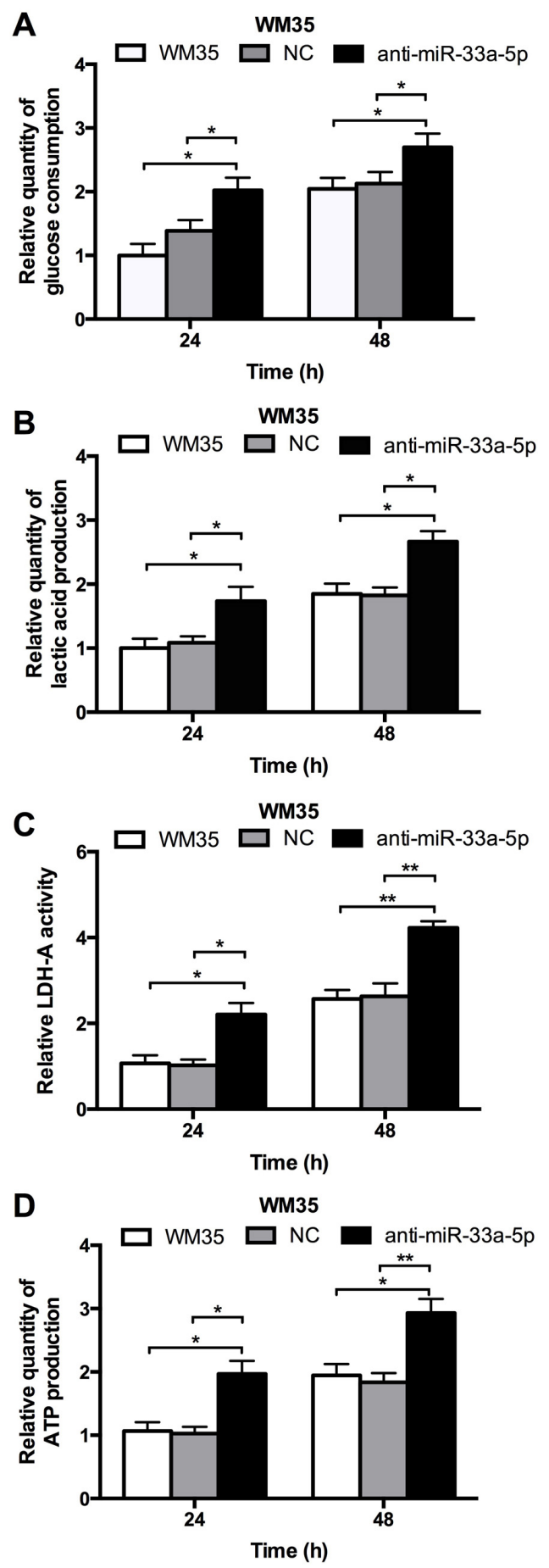

and sh3-HIF-1 $\alpha$ plasmids but were significantly upregulated in WM451cells after co-transfection with pre-miR-33a-5p and HIF-1 $\alpha$ plasmids. These findingsconfirmed that miR-33a-5p plays an inhibitory role in glycolysis in MM cells by negatively regulating HIF- $1 \alpha$.
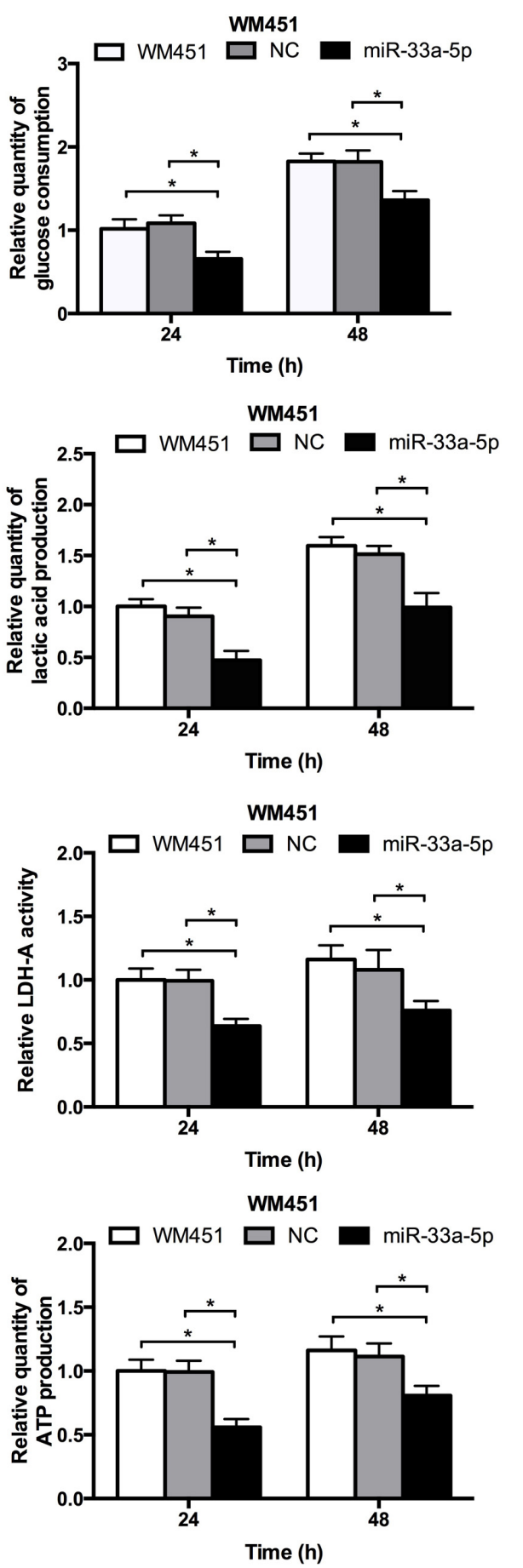

Figure 3: miR-33a-5p plays an inhibitory role in glycolysis in MM cells. (A) Glucose consumption was measured by microplate assay, with the value for non-treated cells set as 1. (B) Lactic acid production in WM35 and WM451 cells. Non-treated cells were used for normalization. (C) Activity of LDH-A was analyzed by activity gel assay. (D) ATP production was measured using a luciferin/luciferase assay. $* P<0.05, * * P<0.01$. 
miR-33a-5p enhances radiosensitivity of melanoma cells to $\mathrm{X}$-radiation

As indicated in Figure 6A, administration of increasing doses of radiation resulted in a dose-dependent downward trend in the cell survival rate of WM35 and WM451. In particular, the survival rate of WM35 cells was much higher in anti-miR-33a-5p group, while WM451 cells was lower in the miR-33a-5p group $(P<0.05)$. Considering the cell survival rate under 4 Gy X-ray irradiation were ranged $50 \%$ to $60 \%$ in both
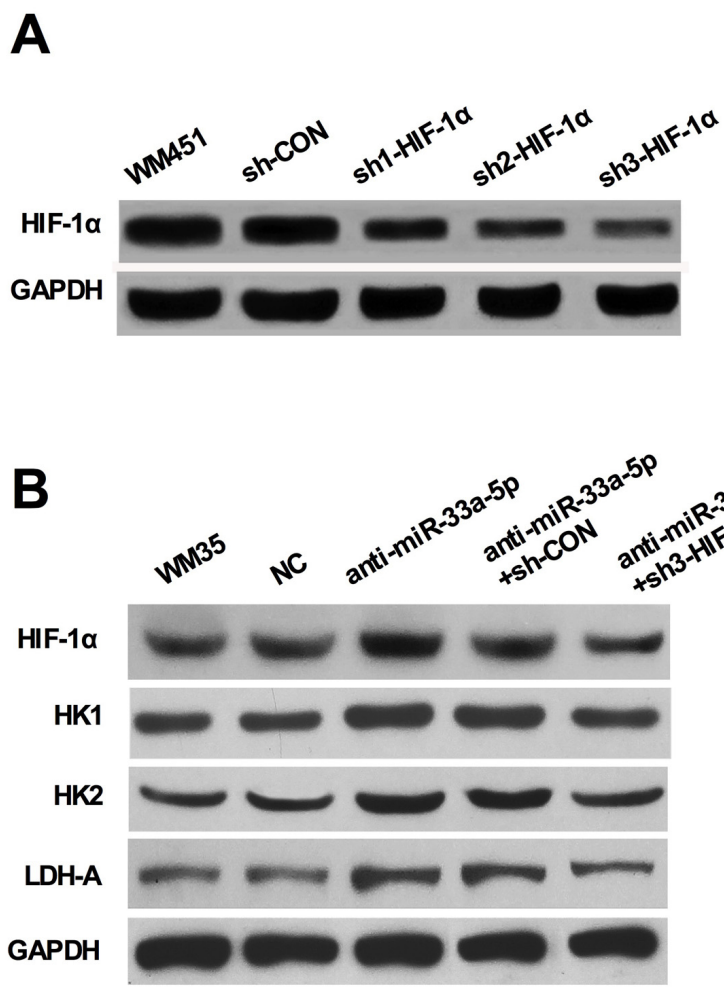

$$
\begin{aligned}
& \text { SP } \\
& \text { LD } \\
& \text { GAP }
\end{aligned}
$$
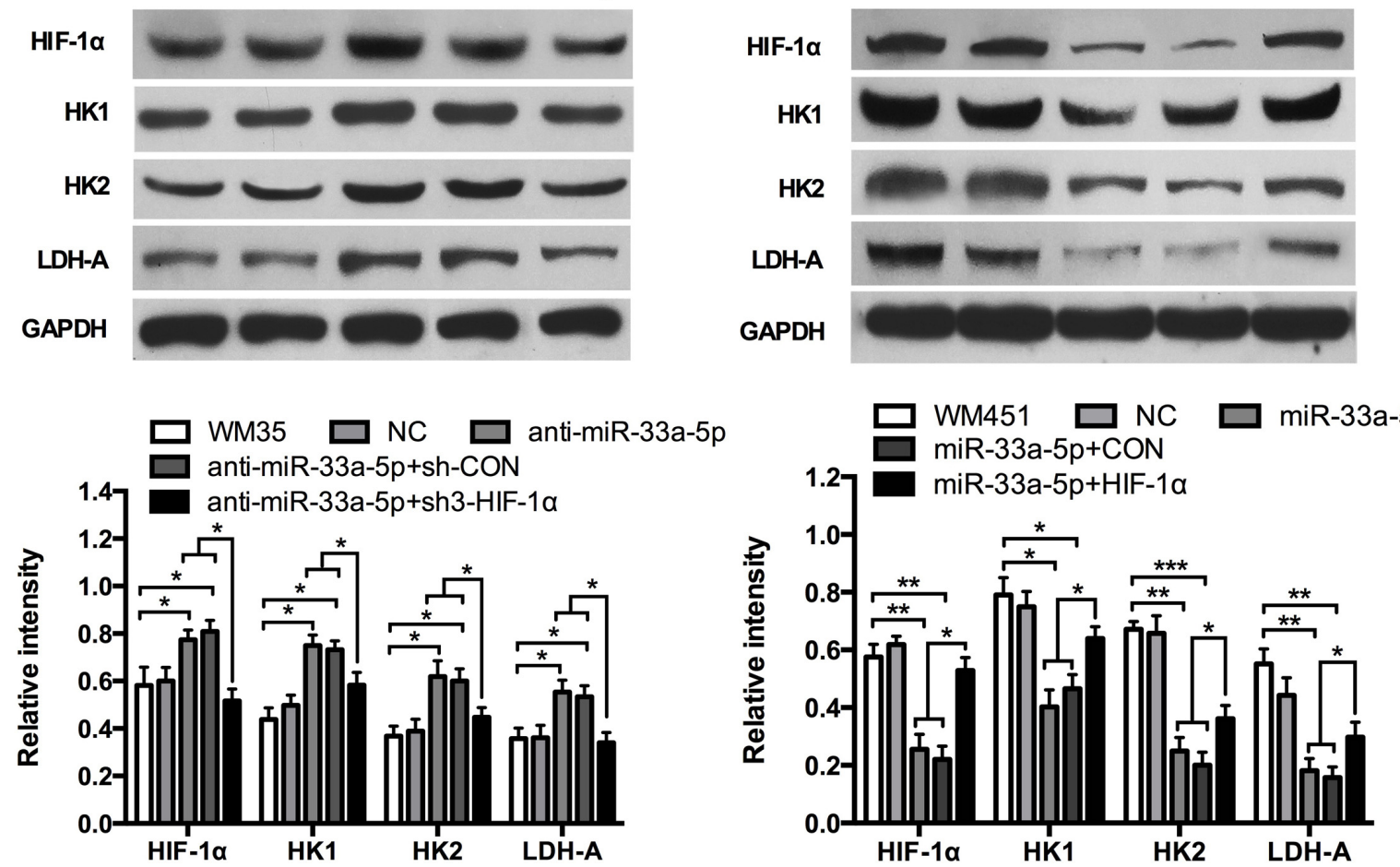

Figure 4: HIF-1a restores the inhibitory effect of miR-33a-5p on glycolysis. (A) Three shRNA expression plasmids targeting HIF-1 $\alpha$ were transfected into WM451 cells, respectively. Western blotting results revealed that the third shRNA sequence had the best inhibitory effect. (B) WM35 cells were transfected with anti-miR-33a-5p plasmid, or co-transfected with anti-miR-33a-5p and sh-HIF-1 $\alpha$ plasmids. WM45 1 cells were transfected with pre-miR-33a-5p plasmid, or co-transfected with pre-miR-33a-5p and HIF-1 $\alpha$ plasmids. HIF-1 $\alpha$, HK1, HK2, and LDH-A protein expression was measured by western blotting. GAPDH protein expression was used as a control for input and normalization. $* P<0.05, * * P<0.01, * * * P<0.001$. 
A

WM35

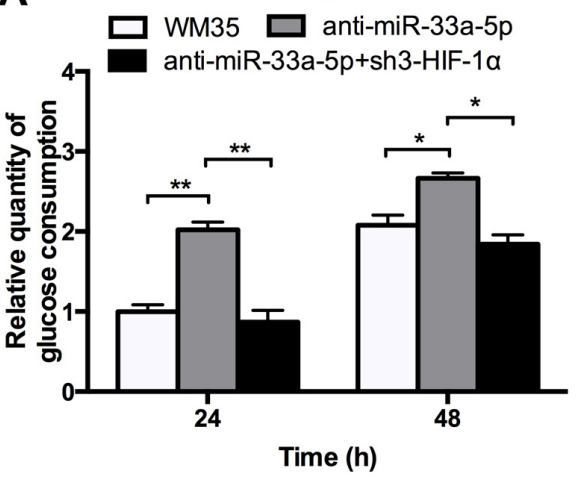

B

WM35

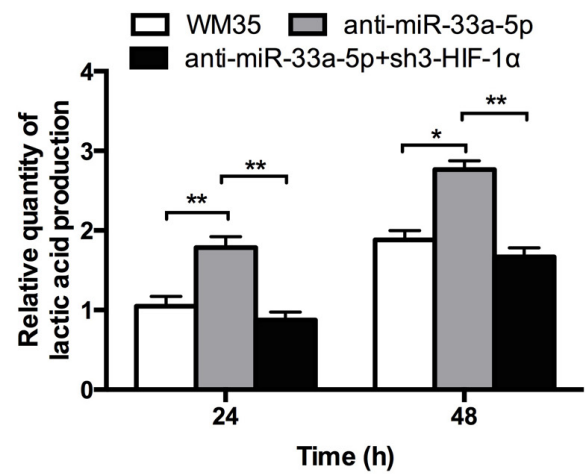

C

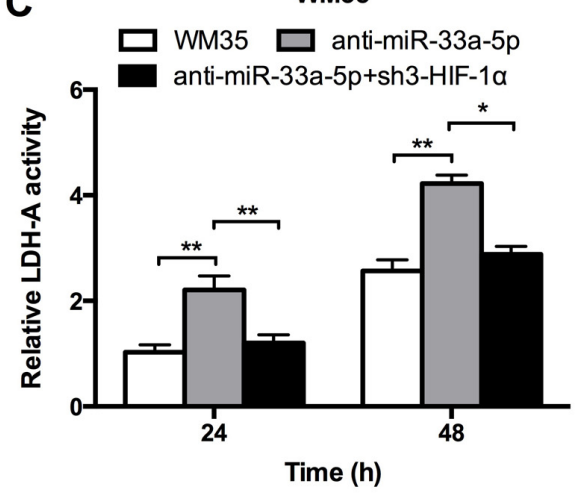

D

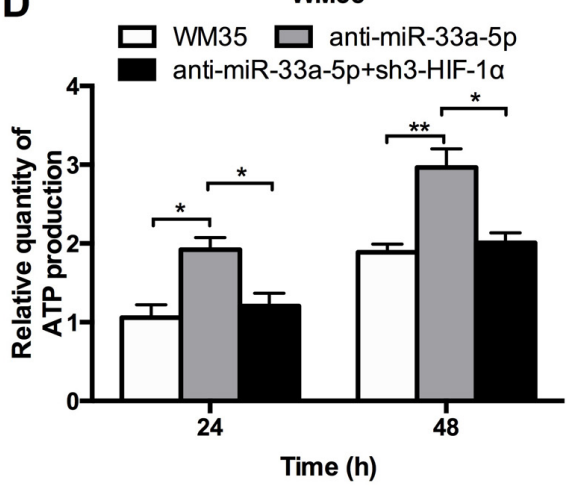

WM451

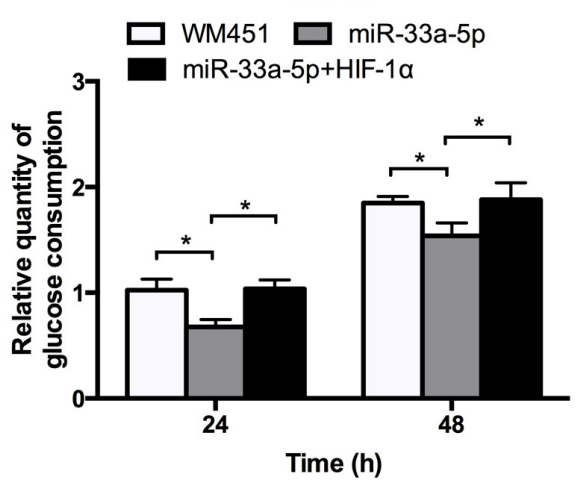

WM451

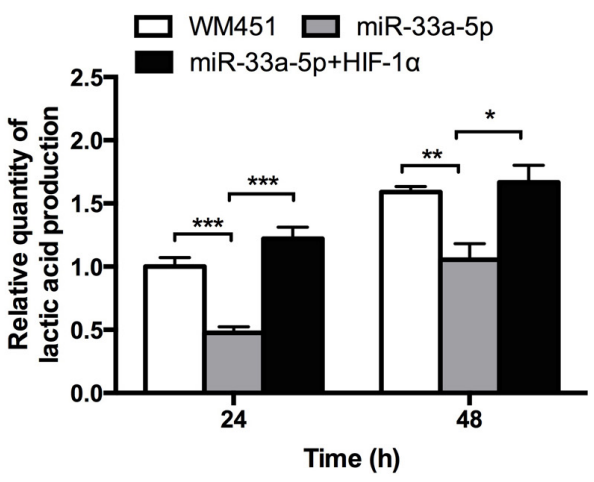

WM451

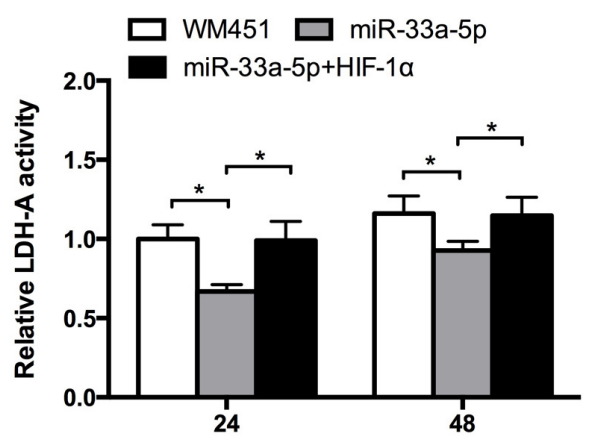

Time (h)

WM451

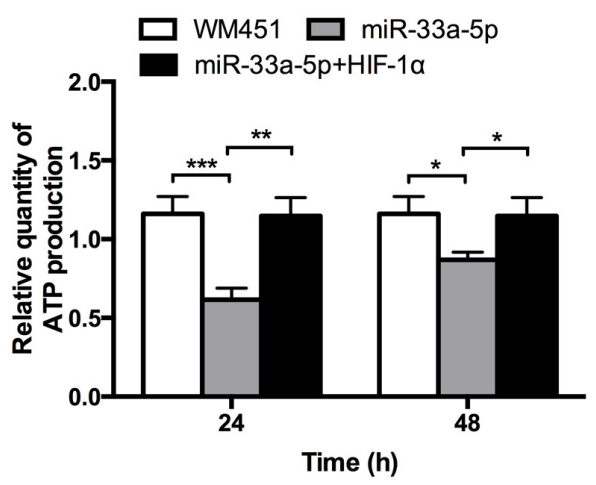

Figure 5: miR-33a-5p/HIF-1 $\alpha$ axis plays an important role on glycolysis. (A) Glucose consumption was measured by microplate assay, with the value for non-treated cells set as 1. (B) Lactic acid production was detected in WM35 and WM451 cells. Untreated cells were used for normalization. (C) Activity of LDH-A was analyzed by activity gel assay. (D) ATP production was measured using a luciferin/luciferaseassay. ${ }^{*} P<0.05, * * P<0.01, * * * P<0.001$. 


\section{miR-33a-5p increases cell radiosensitivity by negatively regulating glycolysis in vivo}

Nude mice were subcutaneously inoculated with WM451 cells, WM451 cells transfected with blank empty vector (NC), or WM451 cells transfected with pre-miR-33a-5p (miR-33a-5p) vector. The results showed that it took 12-14 days after tumor implantation for the tumor volume of each group reached $150 \mathrm{~mm}^{3}$. After tumor development, the mice were treated with irradiation at a total dose of $10 \mathrm{~Gy}$. The growth curve of each group was showed at Figure 6B, which revealed that the tumor volume of nude mice in the miR-33a-5p group was significantly lower than that in unirradiated, WM451, and NC groups $(P<0.05)$.The average volume of the tumors (Figure $6 \mathrm{C}$ ) in the unirradiated, WM451, and $\mathrm{NC}$ groups was $2400.83 \pm 841.23,979.15$ \pm 225.26 and $615.96 \pm 257.78 \mathrm{~mm}^{3}$, respectively, which was notably higher than that in the miR-33a-5p group $\left(246.07 \pm 55.72 \mathrm{~mm}^{3}\right)$. The average tumor mass (Figure 6C) in the unirradiated, WM451, and NC groups was $1.43 \pm 0.39,0.80 \pm 0.14$ and $0.55 \pm 0.20 \mathrm{~g}$, respectively, which was also higher than that in the miR-33a-5p group $(0.24 \pm 0.08 \mathrm{~g})$. To analyze the relationship between radiosensitivity and glycolysis, western blot analysis was performed to measure the HIF-1 $\alpha$, HK1, HK2, and LDH-A protein expression levels in the xenograft tumor (Figure 6D). HIF-1 $\alpha$, HK1, HK2, and LDH-A proteins were significantly downregulated after overexpression of miR-33a-5p. Therefore, melanoma cells with high miR-33a-5p expression level increased radiosensitivity accompanied by downregulation of glycolysis in vivo.

\section{DISCUSSION}

Increasing evidence indicates that microRNAs are associated with tumor radiosensitivity. Zhu et al. [28] found that downregulation of miR-21 enhanced radiosensitivity in nasopharyngeal carcinoma. Another study confirmed that miR-622 induced radioresistance by targeting $\mathrm{Rb}$ in colorectal cancer cells [29]. Liu et al. [30] reported that miR-18a increased radiosensitivity by promoting radiation-induced apoptosis in cervical cancer cells. In our previous study, we demonstrated that miR-33a functions as a tumor suppressor by targeting HIF- $1 \alpha$ in melanoma cells [23]. The present study aim to investigate whether miR-33a-5p restores malanoma radioresistance.

We found that miR-33a-5p was significantly downregulated in melanoma tissue compared with nevus tissue. Interestingly, miR-33a-5p expression was much lower in metastatic tissue than in primary tissues. miR$33 a-5 p$ expression was also notably reduced in MM cells. These results verified those reported previously by us. To further explore the inhibitory effect of miR-33a-5p in vitro, WM35 and WM451 cells were selected for subsequent experiments. MTT assays revealed that cell proliferation was upregulated after inhibition of miR$33 a-5 p$ in WM35 cells, but notably downregulated after overexpression of miR-33a-5p in WM451 cells. Therefore, miR-33a-5p suppresses proliferation in MM cells.

Although less efficient than oxidative phosphorylation in the yield of adenosine triphosphate, glycolysis can more rapidly provide cancer cells with energy and the metabolic intermediates needed for macromolecular biosynthesis, conferring advantages to cancer cells under conditions of limited nutrient supply [31]. Therefore, targeting glycolysis seems to be an effective tumor therapy strategy. After showing that miR33a-5p could inhibit MM cell proliferation, we focused on the effect of miR-33a-5p on glycolysis in MM cells. The three key enzymes of glycolysis are HK1, HK2, and LDAH [32]. We found that the expression of HIF-1 $\alpha$, HK1, HK2, and LDH-A was increased after inhibition of miR-33a-5p in WM35 cells, but reduced after miR-33a-5p overexpression in WM451 cells. Moreover, knockdown of miR-33a-5p promoted glycolysis, as measured by glucose consumption, lactic acid production, LDH-A activity, and ATP production, whereas upregulation of miR-33a-5p inhibited glycolysis in MM cells. In our previous study, we confirmed that miR-33a-5p functions as tumor suppressor mainly via directly binding HIF-1 $\alpha$ 3'UTR [23]. HIF-1 $\alpha$ is one of hypoxic-related genes helps tumor cells adapting to the low nutrient and oxygen microenviroment. There is an obvious positive correlation between HIF- $1 \alpha$ and glycolysis during tumorigenesis [33, 34]. miR-33a-5p plays an inhibitory role in glycolysis in melanoma, suggesting HIF-1 $\alpha$ may involve in this activity. We further confirmed that upregulation of HIF- $1 \alpha$ reversed the inhibitory effect of miR-33a-5p overexpression on glycolysis in WM451 cells, whereas downregulation of HIF- $1 \alpha$ reversed the promoting effect of miR-33a-5p inhibition on glycolysis in WM35 cells. HK1/HK2 as well as LDAH was proved upregulated by HIF-1 $\alpha$ overexpression, while was inhibited by knock-down HIF-1 $\alpha$, which were basically in accord with previous studies [35]. HK2 is considered as a downstream of HIF$1 \alpha$ in fermentation, which acts as a rate-limiting enzyme and involves in one irreversible step of glycolysis [36]. The results mentioned above suggesting that miR-33a-5p represses glycolysis mainly via inhibition of HIF-1 $\alpha$ in melanoma.

Radioresistance is one of major problems encountered in cancer therapy. Previous studies have strongly suggested that glycolysis leads to radiation resistance of cancer cells [37]. HIF-1 $\alpha$ has recently been shown being participated in tumor glycometabolism. Jiang $\mathrm{S}$ et al. [38] found that HIF-1 $\alpha$ was upregulated by miR-21 in radioresistant non-small cell lung cancer cells. Considering miR-33a-5p acts as an upstream factor of HIF-1 $\alpha$, MTT assays were performed to measure the cell survival rate of MM cells under X-ray irradiation. The results indicated that the radiosensitivity of MM cells was 
enhanced by overexpression of miR-33a-5p. Accordingly, we suggest that the radiosensitizing effects of miR-33a-5p in MM cells in vitro may be mediated by suppression of glycolysis. WM35 cells are lowly tumorigenic and even non-tumorigenic in nude mice [39], Therefore only WM451 cells were performed to explorethe antitumor effect of miR-33a-5p. Finally, in vivo xenograft experiments revealed that the tumor burden of melanoma was reduced by radiotherapy, and high expression of miR-33a-5p in MM cells increased radiosensitization accompanied by downregulation of glycolysis. These findings indicating that miR-33a-5p functions as a tumor suppressor by inhibiting HIF-1 $\alpha$-mediated glycolysis (Figure 7). However, there are some questions remain to be clarify. Understanding why these cells under-expressed miR-33a-5p is the next step in our further education.
A
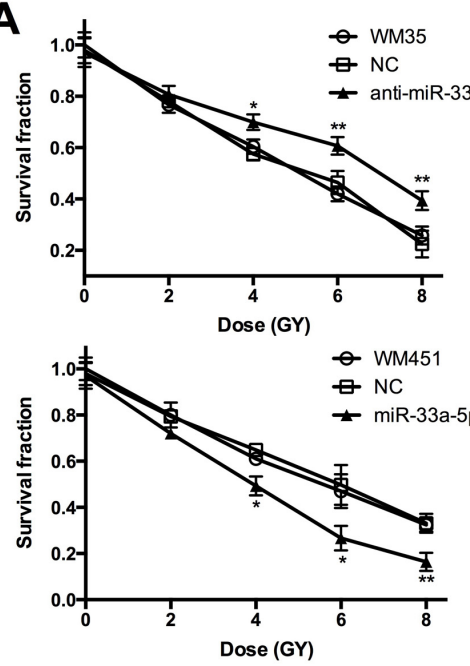

C

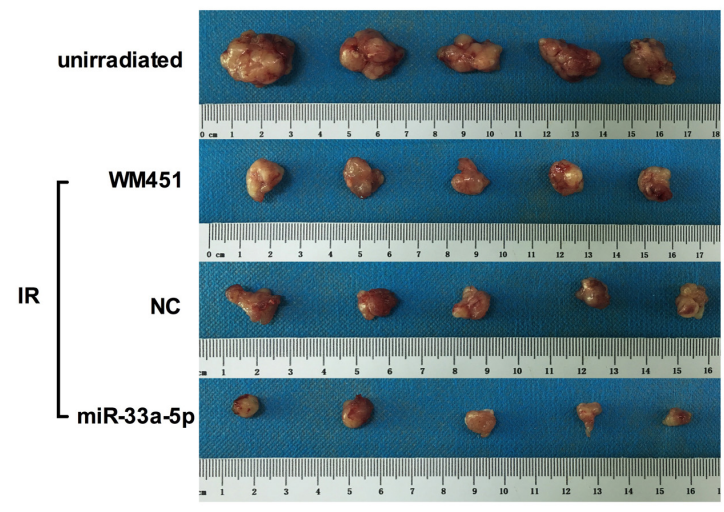

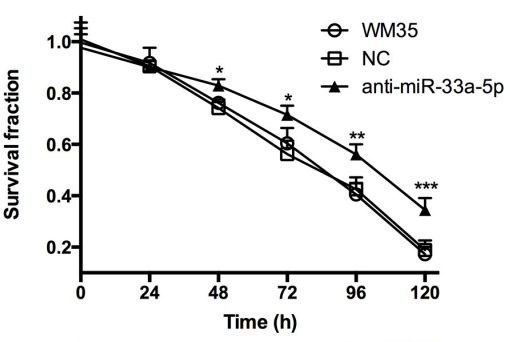

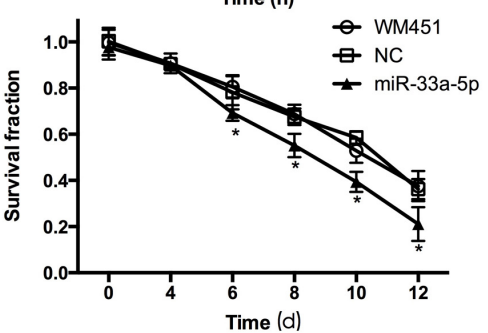

B

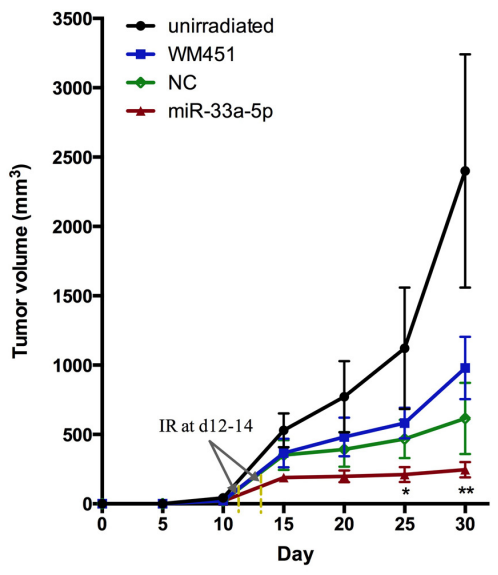

D
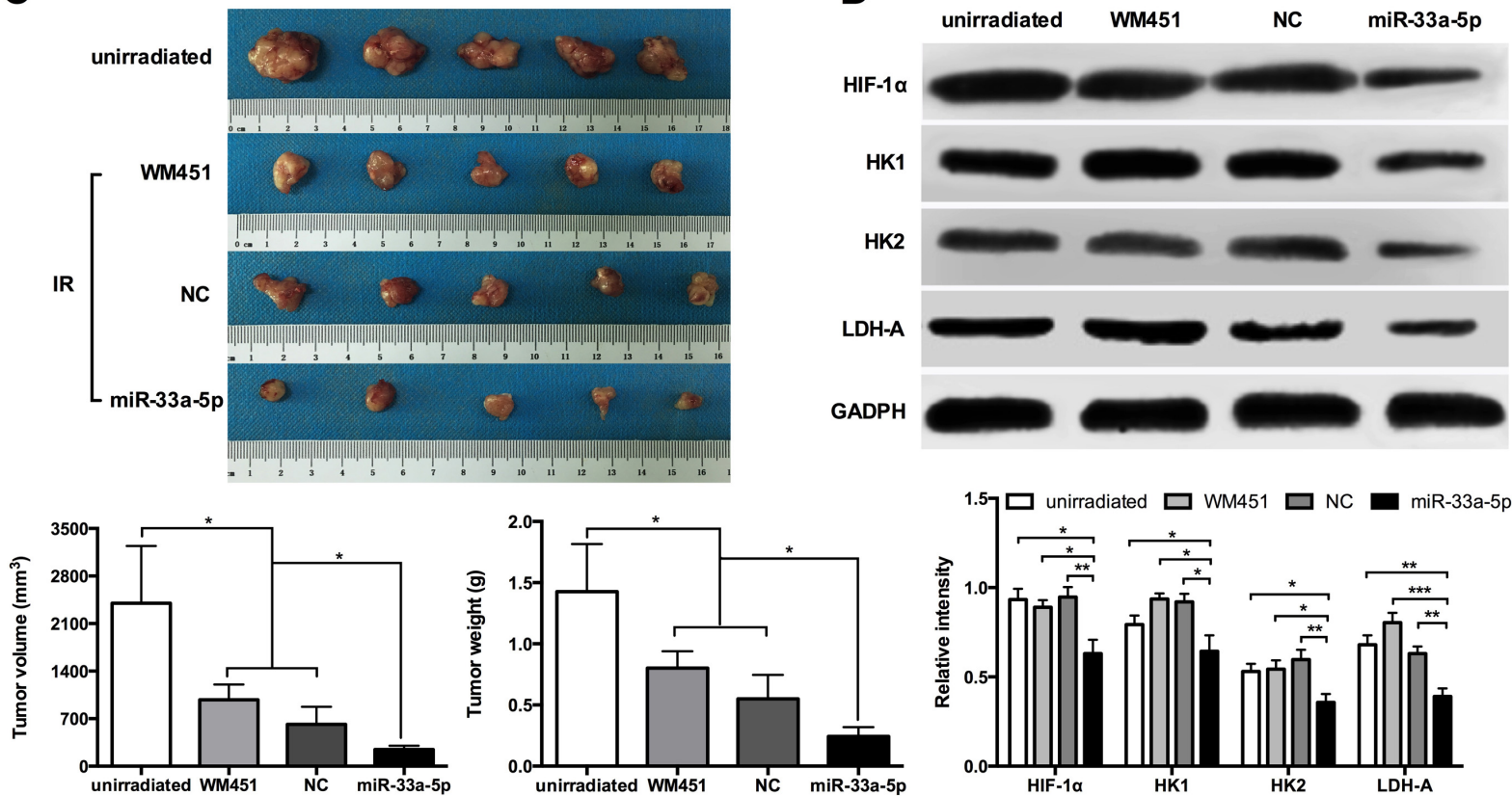

Figure 6: miR-33a-5p increases cell radiosensitivity by negatively regulating glycolysis in MM. (A) MTT assay was performed to measure the cell survival rate of WM35 and WM451 cells at 8 days under $0,2,4,6$, and 8 Gy irradiation. The survival rate was significantly lower in the miR-33a-5p group compared with the non-transfected and control groups. MTT assay was also performed to observe the cell survival rate at the indicated time points under 4 Gy X-ray irradiation. (B) Growth curve of nude mice with different levels of miR-33a-5p expression. Day 0 means the day of injection of tumor cells. Arrows indicated the day radiotherapy began for mice in WM451, NC, and miR-33a-5p groups. (C) Representative images of subcutaneous tumors at day 30. Tumor volume and weight of WM451 xenografts in the unirradiated, WM451, NC, and miR-33a-5p groups. The results were analyzed using one-way ANOVA. (D) Western blotting of HIF-1 $\alpha$, HK1, HK2, and LDH-A protein expression in WM451 xenografts. GAPDH protein expression was used as a control for input and normalization. IR: irradiation. ${ }^{*} P<0.05,{ }^{*} P<0.01, * * * P<0.001$. 
In summary, we suggest that miR-33a-5p promotes radiosensitivity by negatively regulating glycolysis in MM cells. Therefore, targeting the miR-33a-5p/glycolysis pathway may provide a new direction for radiotherapy of melanoma.

\section{MATERIALS AND METHODS}

\section{Reagents}

Glucose-Dulbecco's modified Eagle's medium (DMEM), fetal bovine serum (FBS), Trizol reagent, miRNA reverse transcription kit, and Lipofectamine 2000 were purchased from Life Technologies (Waltham, MA). BCA protein assay kits were purchased from Beyotime (Haimen, China). Pre-miR-33a-5p lentivirus plasmid, anti-miR-5p lentivirus plasmid, HIF-1 $\alpha$ overexpressing plasmid, and HIF-1 $\alpha$ shRNA plasmid were purchased from DingGuoChangShengBiotech (Beijing, China). Sequences of the insert in plasmids were listed in Supplementary Table 1. miRNA qRT-PCR Detection Kit was purchased from GeneCopoeia, Rockville, MD, USA. RevertAid ${ }^{\mathrm{TM}}$ H Minus First Strand cDNA Synthesis Kit was purchased from Fermentas. MTT was purchased from Biosharp (Hefei, Anhui, China). The Power SYBR Green kit was purchased from TOYOBO (Osaka, Japan). The glucose assay kit, lactate assay kit, and LDH activity assay kit were from Biovision (Milpitas, CA). The ATP assay Kit was from Beyotime Biotechnology (Shanghai). Mouse anti-HIF-1 $\alpha$ monoclonal antibody, mouse antiglyceraldehyde-3-phosphate dehydrogenase (GAPDH) monoclonal antibody, and rabbit anti-mouse secondary antibody were purchased from Abcam (Cambridge, UK) and anti-lactate dehydrogenase A (LDH-A) antibody was from Epitomics (Burlingame, CA).

\section{Samples}

Twenty melanoma and match nevus tissues were collected by the Department of Pathology at the Second Xiangya Hospital and Third Xiangya Hospital, Central South University between 2004 and 2014, following informed consent from each of the patients and approval by the Ethics Committee of Third Xiangya Hospital, Central South University. None of the melanoma patients received chemotherapy or radiotherapy before surgery. All specimens were fixed in 10\% neutral formalin and embedded in paraffin.

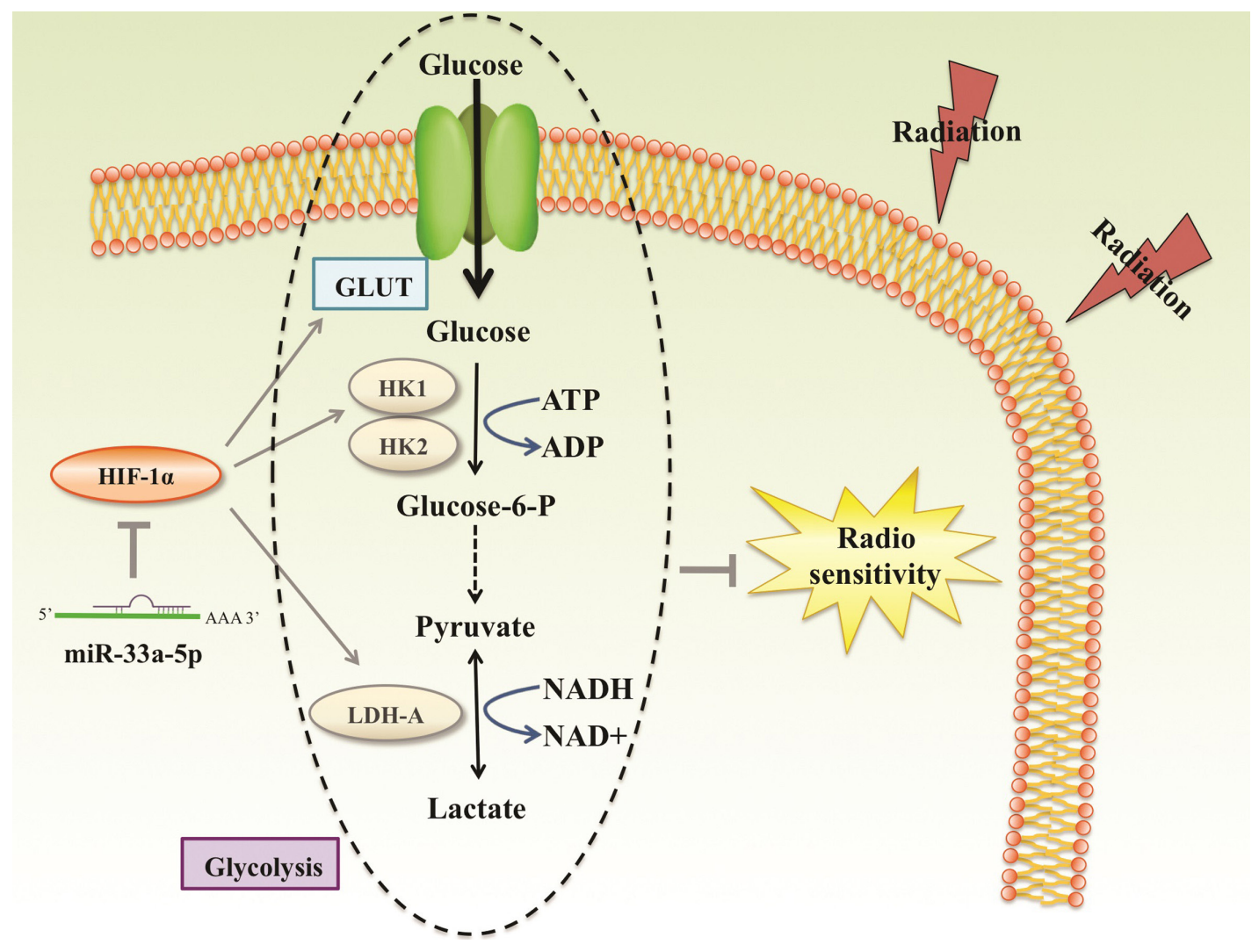

Figure 7: Reported and potential mechanisms for the regulation of the radiosensetivity by miR-33a-5p in MM. miR$33 a-5 p$ inhibits the process of glycolysis mainly via negatively regulating HIF-1 $\alpha$, a closely related gene of glycolysis. Glycolysis products such as pyruvate and lactate played important roles in radioresistance. miR-33a-5p increased MM cell radiosensetivity account for downregulation glycolysis level. 


\section{Cell culture}

Human malignant melanoma cell lines A375, WM35, WM451, and SK-MEL-1 were obtained from the Cell Bank of Central South University, Changsha, China. Primary human melanocytes (HM) were purchased from Shanghai XinYu Biological Technology Co., Ltd (Shanghai, China).Cells were cultured in DMEM supplemented with $10 \% \mathrm{FBS}$ at $37^{\circ} \mathrm{C}$ in a humidified incubator containing $5 \% \mathrm{CO}_{2}$.

\section{Transfection}

Transfection was performed using Lipofectamine 2000 in accordance with the manufacturer's instructions. In brief, for functional analysis MM cells were transfected with the premiR-33a-5p lentivirus plasmid, anti-miR-33a-5p lentivirus plasmid, HIF-1 $\alpha$ overex pressing plasmid, or HIF-1 $\alpha$ shRNA plasmid.

\section{Real-time RT-PCR assay}

Total RNA was extracted with Trizol agent in accordance with the manufacturer's instructions. For the analysis of miRNA expression, a miRNA reverse transcription kit was used to convert RNA into cDNA according to the manufacturer's protocol. Real-time PCR was performed using a miRNA qRT-PCR Detection Kit on an ABI 7500 thermocycler (Life Technologies). The U6 gene was used as an endogenous control. For the analysis of mRNA expression, Revert Aid ${ }^{\mathrm{TM}} \mathrm{H}$ Minus First Strand cDNA Synthesis Kit was used to convert RNA into cDNA and real-time PCR was performed using a Power SYBR Green kit on an ABI 7500 thermocycler. GAPDH was used as an endogenous control. For both mRNA and miRNA, the relative expression was analyzed by the $2^{-\Delta \Delta \mathrm{Ct}}$ method. The primers used were as follows: miR33a-5p, 5'-GATCCTCAGTGCATTGTAGTTGC-3' and reverse 5'-CTCTGTCTCTCGTCTTGTTGGTAT-3'; U6, 5'-ATTGGAACGATACAGAGAAGATT-3' and reverse 5'-GGAACGCTTCACGAATTTG-3'.

\section{Cell viability assay}

For all groups, 10,000 cells per well were plated in a 96-well plate. After treatment, the plates were incubated for $0,24,48,72,96$ or $120 \mathrm{~h}$ at $37^{\circ} \mathrm{C}, 5 \% \mathrm{CO}_{2}$. To assess cell viability, the MTT assay was performed according to the manufacturer's manual. Briefly, $10 \mu \mathrm{lof} 5 \mathrm{mg} /$ $\mathrm{ml}$ MTT reagent in PBS was added to each well and incubated for $4 \mathrm{~h}$ at $37^{\circ} \mathrm{C}, 5 \% \mathrm{CO}_{2}$. The supernatant was removed and $100 \mu \mathrm{l}$ of DMSO was added. Absorbance was detected at $450 \mathrm{~nm}$ with a Microplate Reader (BioRad, USA). Each assay was performed in triplicate wells and repeated three times.

\section{Western blotting}

Protein was extracted from the indicated cells using RIPA lysis buffer. Protein assay reagents (Beyotime) were used to measure the protein concentration. A total of $60 \mu \mathrm{g}$ of protein was separated with $12 \%$ SDS-PAGE and transferred to a PVDF membrane, which was blocked in 5\% nonfat dried milk in PBS at room temperature for $2 \mathrm{~h}$. The membrane was incubated with mouse anti-HIF$1 \alpha$ antibody or mouse anti-GAPDH monoclonal antibody overnight at $4^{\circ} \mathrm{C}$ and then with goat anti-mouse secondary antibody for $2 \mathrm{~h}$. Enhanced chemiluminescence reagent was used to detect the signal on the membrane. Data were analyzed by densitometry using Image-Pro plus software 6.0 and normalized to GAPDH expression. The western blot experiments were repeated at least three times.

\section{Measurement of glycolysis}

Glucose consumption was detected using a glucose assay kit according to the manufacturer's protocol. The absorbance at $570 \mathrm{~nm}$ was measured with a plate reader (Thermo Multiskan MK3 spectrophotometer; Thermo Fisher Scientific, Waltham, MA). Lactate levels in the culture media were determined using a lactate assay kit according to the manufacturer's protocol.

Total intracellular LDH activity was examined using an LDH activity assay kit according to the manufacturer's instructions. The results were normalized to the total protein concentration. Briefly, $2 \times 10^{5}$ cells per well were plated in a 24-well plate for $48 \mathrm{~h}$. The cells were collected, washed, and protein was extracted for measurement of LDH-A activity.

Cellular ATP was measured using a luciferin/ luciferase assay kit. Cells were permeabilized prior to the addition of luciferin substrate and luciferase. Bioluminescence was assessed on an LUMATLB9507 luminometer (EG\&G Berthold, Bad Wildbad, Germany) and cellular ATP content (nmol/mg) was determined using a curve for the luminescence of standard dilutions of ATP. ATP content was normalized to protein content.

\section{Radiation studies}

A Varian Truebeam linear accelerator (Varian, USA) was used for X-ray irradiation. Cells at a density of $3 \times 10^{3}$ cells/well were irradiated with different doses of X-rays $(100 \mathrm{~cm}, 4 \mathrm{~Gy} / \mathrm{min})$ after $48 \mathrm{~h}$ of transfection. Animal experimentation was performed according to NIH Animal Care guidelines, and the entire experiment was approved by the Ethics Committee of Third Xiangya Hospital, Central South University. Male Balb/c Nu/nu mice aged approximately 4-6 weeks were obtained from Third Xiangya Hospital of Central South University and $2 \times 10^{6}$ WM451 cells were subcutaneously injected into 
the flanks of the mice. When the tumor volume reached $150 \mathrm{~mm}^{3}$, the mice were treated with irradiation at a total dose of 10 Gy for 5 consecutive days. Nude mice were sacrificed 30 days after tumor implantation, and tumor volume and weight were measured. Tumor volume was calculated using the formula $\mathrm{V}\left(\mathrm{cm}^{3}\right)=0.5 \times \mathrm{a} \times \mathrm{b}^{2}$, where $\mathrm{a}$ is the maximum long diameter and $\mathrm{b}$ is the maximum transverse diameter.

\section{Statistical analysis}

All experiments were repeated at least three times, and the results are expressed as the mean $\pm \mathrm{SD}(n=3)$. SPSS18.0 software (SPSS, Inc., Chicago, IL, USA) was used to perform statistical analysis. Statistical analysis of differences was performed by one-way analysis of variance (ANOVA). ${ }^{*} P<0.05$ was considered statistically significant.

\section{Authors' contributions}

Jianda Zhou and Ke Cao designed the experiments and drafted the manuscript. Yao Chen, Jingjing Li and Jia Chen performed the experiments. Li Qian, Aijun Wang, Yan Cheng, and Xiang Chen participated in the design of the study and performed the statistical analysis. Jingtian Tang, Shijie Tang and Wei Xiong supervised all of the work and revised the manuscript. All of the authors have read and approved the final manuscript.

\section{ACKNOWLEDGMENTS AND FUNDING}

This work was supported by the National Natural Science Foundation of China (No. 81572689, 81372140, 81301688, 81272192, 81572965), Program for New Century Excellent Talents in University (No. NCET-110527), Natural Science Foundation of Hunan Province (No. 2016JJ6154), Project of the Department of Science and Technology of Hunan Province (No. 2015SK2066, 2014SK2018 and 2013FJ6003), 125 Talent Project/ New xiangya project of the Third Xiangya Hospital of Central South University. Fundamental Research Funds for the Central Universities of Central South University (2017zzts220).

\section{CONFLICTS OF INTEREST}

The authors declare no conflicts of interests.

\section{REFERENCES}

1. Trotter SC, Sroa N, Winkelmann RR, Olencki T, Bechtel M. A Global Review of Melanoma Follow-up Guidelines. J Clin Aesthet Dermatol. 2013; 6:18-26.
2. Xie B, Cao K, Li J, Chen J, Tang J, Chen X, Xia K, Zhou X, Cheng Y, Zhou J, Xie H. Hmgb1 inhibits Klotho expression and malignant phenotype in melanoma cells by activating NF-кB. Oncotarget. 2016; 7:80765-80782. https://doi. org/10.18632/oncotarget.12623.

3. Linos E, Swetter SM, Cockburn MG, Colditz GA, Clarke CA. Increasing burden of melanoma in the United States. J Invest Dermatol. 2009; 129:1666-1674.

4. Strickland LR, Pal HC, Elmets CA, Afaq F. Targeting drivers of melanoma with synthetic small molecules and phytochemicals. Cancer Lett. 2015; 359:20-35.

5. Zeng Q, Wang Q, Chen X, Xia K, Tang J, Zhou X, Cheng Y, Chen Y, Huang L, Xiang H, Cao K, Zhou J. Analysis of lncRNAs expression in UVB-induced stress responses of melanocytes. J Dermatol Sci. 2016; 81:53-60.

6. Hirschhaeuser F, Sattler UG, Mueller-Klieser W. Lactate: a metabolic key player in cancer. Cancer Res. 2011; 71:6921-6925.

7. Sattler UG, Mueller-Klieser W. The anti-oxidant capacity of tumour glycolysis. Int J Radiat Biol. 2009; 85:963-971.

8. Wang Z, Wang N, Liu P, Peng F, Tang H, Chen Q, Xu R, Dai Y, Lin Y, Xie X, Peng C, Situ H. Caveolin-1, a stressrelated oncotarget, in drug resistance. Oncotarget. 2015; 6:37135-37150. https://doi.org/10.18632/oncotarget.5789.

9. Koukourakis MI, Kakouratos C, Kalamida D, Bampali Z, Mavropoulou S, Sivridis E, Giatromanolaki A. Hypoxiainducible proteins HIF1alpha and lactate dehydrogenase LDH5, key markers of anaerobic metabolism, relate with stem cell markers and poor post-radiotherapy outcome in bladder cancer. Int J Radiat Biol. 2016; 92:353-363.

10. Shimura $T$, Noma N, Sano Y, Ochiai Y, Oikawa T, Fukumoto M, Kunugita N. AKT-mediated enhanced aerobic glycolysis causes acquired radioresistance by human tumor cells. Radiother Oncol. 2014; 112:302-307.

11. Zhai X, Yang Y, Wan J, Zhu R, Wu Y. Inhibition of LDH-A by oxamate induces G2/M arrest, apoptosis and increases radiosensitivity in nasopharyngeal carcinoma cells. Oncol Rep. 2013; 30:2983-2991.

12. Dwarakanath BS, Singh D, Banerji AK, Sarin R, Venkataramana NK, Jalali R, Vishwanath PN, Mohanti BK, Tripathi RP, Kalia VK, Jain V. Clinical studies for improving radiotherapy with 2-deoxy-D-glucose: present status and future prospects. J Cancer Res Ther. 2009; 5:S21-26.

13. Sharma PK, Dwarakanath BS, Varshney R. Radiosensitization by 2-deoxy-D-glucose and 6-aminonicotinamide involves activation of redox sensitive ASK1-JNK/p38MAPK signaling in head and neck cancer cells. Free Radic Biol Med. 2012; 53:1500-1513.

14. Sharma PK, Bhardwaj R, Dwarakanath BS, Varshney R. Metabolic oxidative stress induced by a combination of 2-DG and 6-AN enhances radiation damage selectively in malignant cells via non-coordinated expression of antioxidant enzymes. Cancer Lett. 2010; 295:154-166. 
15. Ambros V. The functions of animal microRNAs. Nature. 2004; 431:350-355.

16. Suzuki M, Cao K, Kato S, Komizu Y, Mizutani N, Tanaka K, Arima C, Tai MC, Yanagisawa K, Togawa N, Shiraishi T, Usami N, Taniguchi T, et al. Targeting ceramide synthase 6-dependent metastasis-prone phenotype in lung cancer cells. J Clin Invest. 2016; 126:254-265.

17. Luo C, Merz PR, Chen Y, Dickes E, Pscherer A, Schadendorf D, Eichmüller SB. MiR-101 inhibits melanoma cell invasion and proliferation by targeting MITF and EZH2. Cancer Lett. 2013; 341:240-247.

18. Ma HW, Xie M, Sun M, Chen TY, Jin RR, Ma TS, Chen QN, Zhang EB, He XZ, De W, Zhang ZH. The pseudogene derived long noncoding RNA DUXAP8 promotes gastric cancer cell proliferation and migration via epigenetically silencing PLEKHO1 expression. Oncotarget. 2016; 8:52211-52224. https://doi.org/10.18632/oncotarget.11075.

19. Xu X, Chen R, Li Z, Huang N, Wu X, Li S, Li Y, Wu S. MicroRNA-490-3p inhibits colorectal cancer metastasis by targeting TGFbetaR1. BMC Cancer. 2015; 15:1023.

20. Yin H, Song P, Su R, Yang G, Dong L, Luo M, Wang B, Gong B, Liu C, Song W, Wang F, Ma Y, Zhang J, et al. DNA Methylation mediated down-regulating of MicroRNA-33b and its role in gastric cancer. Sci Rep. 2016; 6:18824.

21. Du M, Zhang Y, Mao Y, Mou J, Zhao J, Xue Q, Wang D, Huang J, Gao S, Gao Y. MiR-33a suppresses proliferation of NSCLC cells via targeting METTL3 mRNA. Biochem Biophys Res Commun. 2017; 482:582-589.

22. Kuo PL, Liao SH, Hung JY, Huang MS, Hsu YL. MicroRNA-33a functions as a bone metastasis suppressor in lung cancer by targeting parathyroid hormone related protein. Biochim Biophys Acta. 2013; 1830:3756-3766.

23. Zhou J, Xu D, Xie H, Tang J, Liu R, Li J, Wang S, Chen X, Su J, Zhou X, Xia K, He Q, Chen J, et al. miR-33a functions as a tumor suppressor in melanoma by targeting HIF-1 $\alpha$. Cancer Biol Ther. 2015; 16:846-855.

24. Metheni M, Lombès A, Bouillaud F, Batteux F, Langsley G. HIF-1 $\alpha$ induction, proliferation and glycolysis of Theileriainfected leukocytes. Cell Microbiol. 2015; 17:467-472.

25. Cuninghame S, Jackson R, Zehbe I. Hypoxia-inducible factor 1 and its role in viral carcinogenesis. Virology. 2014; 456-457:370-383.

26. Semenza GL. HIF-1 mediates metabolic responses to intratumoral hypoxia and oncogenic mutations. J Clin Invest. 2013; 123:3664-3671.

27. Huang SW, Kao JK, Wu CY, Wang ST, Lee HC, Liang SM, Chen YJ, Shieh JJ. Targeting Aerobic Glycolysis and HIF-1 $\alpha$ Expression Enhance Imiquimod-induced Apoptosis in Cancer Cells. Oncotarget. 2014; 5:1363-1381. https://doi. org/10.18632/oncotarget.1734.

28. Zhu H, Zhu X, Cheng G, Zhou M, Lou W. Downregulation of microRNA-21 enhances radiosensitivity in nasopharyngeal carcinoma. Exp Ther Med. 2015; 9:2185-2189.
29. Ma W, Yu J, Qi X, Liang L, Zhang Y, Ding Y, Lin X, Li G, Ding Y. Radiation-induced microRNA-622 causes radioresistance in colorectal cancer cells by downregulating Rb. Oncotarget. 2015; 6:15984-15994. https:// doi.org/10.18632/oncotarget.3762.

30. Liu S, Pan X, Yang Q, Wen L, Jiang Y, Zhao Y, Li G. MicroRNA-18a enhances the radiosensitivity of cervical cancer cells by promoting radiation-induced apoptosis. Oncol Rep. 2015; 33:2853-2862.

31. Gonzalez CD, Alvarez S, Ropolo A, Rosenzvit C, Bagnes MF, Vaccaro MI. Autophagy, Warburg, and Warburg reverse effects in human cancer. Biomed Res Int. 2014; 2014:926729.

32. Massari F, Ciccarese C, Santoni M, Iacovelli R, Mazzucchelli R, Piva F, Scarpelli M, Berardi R, Tortora G, Lopez-Beltran A, Cheng L, Montironi R. Metabolic phenotype of bladder cancer. Cancer Treat Rev. 2016; 45:46-57.

33. Cheng SC, Quintin J, Cramer RA, Shepardson KM, Saeed S, Kumar V, Giamarellos-Bourboulis EJ, Martens JH, Rao NA, Aghajanirefah A, Manjeri GR, Li Y, Ifrim DC, et al. mTOR- and HIF-1alpha-mediated aerobic glycolysis as metabolic basis for trained immunity. Science. 2014; 345:1250684.

34. Palsson-McDermott EM, Curtis AM, Goel G, Lauterbach MA, Sheedy FJ, Gleeson LE, van den Bosch MW, Quinn SR, Domingo-Fernandez R, Johnston DG, Jiang JK, Israelsen WJ, Keane J, et al. Pyruvate kinase M2 regulates Hif-1alpha activity and IL1 beta induction and is a critical determinant of the warburg effect in LPS-activated macrophages. Cell Metab. 2015; 21:65-80.

35. Liu L, Wang Y, Bai R, Yang K, Tian Z. MiR-186 inhibited aerobic glycolysis in gastric cancer via HIF-1 $\alpha$ regulation. Oncogenesis. 2016; 5:e224.

36. Qiu MZ, Han B, Luo HY, Zhou ZW, Wang ZQ, Wang FH, $\mathrm{Li} \mathrm{YH}, \mathrm{Xu} \mathrm{RH}$. Expressions of hypoxia-inducible factor1alpha and hexokinase-II in gastric adenocarcinoma: the impact on prognosis and correlation to clinicopathologic features. Tumour Biol. 2011; 32:159-166.

37. Zhao F, Ming J, Zhou Y, Fan L. Inhibition of Glut1 by WZB117 sensitizes radioresistant breast cancer cells to irradiation. Cancer Chemother Pharmacol. 2016; 77:963-972.

38. Jiang S, Wang R, Yan H, Jin L, Dou X, Chen D. MicroRNA-21 modulates radiation resistance through upregulation of hypoxia-inducible factor- $1 \alpha$-promoted glycolysis in non-small cell lung cancer cells. Mol Med Rep. 2016; 13:4101-4107.

39. Massari NA, Medina VA, Cricco GP, Martinel Lamas DJ, Sambuco L, Pagotto R, Ventura C, Ciraolo PJ, Pignataro O, Bergoc RM, Rivera ES. Antitumor activity of histamine and clozapine in a mouse experimental model of human melanoma. J Dermatol Sci. 2013; 72:252-262. 